\title{
The influence of exposed to corrosion length of rebars on fatigue life of $\mathrm{RC}$ elements
}

\author{
Konstantinos Koulouris ${ }^{1 *}$, Maria Basdeki ${ }^{2}$ and Charis Apostolopoulos ${ }^{3}$ \\ ${ }^{1}$ Dr. Ing. Civil Engineer, Department of Mechanical Engineering and Aeronautics, University of \\ Patras \\ ${ }^{2} \mathrm{PhD}$ Candidate. Civil Engineer, Department of Mechanical Engineering and Aeronautics, University \\ of Patras \\ ${ }^{3}$ Professor, Dr. Ing. Civil Engineer, Department of Mechanical Engineering and Aeronautics, \\ University of Patras
}

\begin{abstract}
Deterioration of reinforced concrete is a main factor on estimation of structures' service lifetime. As it is well known, both corrosion of steel reinforcement and earthquake events, have detrimental effects on structural integrity of RC elements. In this study, the fatigue life of corroded reinforcement is investigated. Bare and embedded (in concrete) specimens of rebars are tested in low cycle fatigue conditions after accelerated corrosion experiments using impressed current technique. Corrosion damage, in terms of mass loss, and the mechanical tests of fatigue are taken account in function of the exposed to corrosion length of reinforcement. The outcomes attained from the experimental study indicate higher mass loss values of specimens with short exposed to corrosion length than the corresponding mass loss values of specimens with long exposed to corrosion length at the same tested corrosion time; subsequently resulting in their reduced fatigue lifetime. Extrapolating the abovementioned results on RC elements in marine environment located in seismic prone areas, issues are raised concerning the assessment of structural integrity and the parameters which are taken into account on monitoring of high importance structures.
\end{abstract}

\section{Introduction}

As it is widely known, corrosion is an issue of great importance and a perpetual challenge to the structural integrity and reliability of RC structures, since it constitutes a major deterioration factor, especially for those structures located on coastal areas. It is straightforward that corrosion has an impact on the useful life of RC structures, even for low levels of corrosion, degrading the mechanical properties of materials. Furthermore, in earthquake prone areas, where RC structures are subjected to dynamic loads, recorded deformations are often below minimum requirements imposed by standards. Thus, ductility plays the key role so as to ensure the bearing capacity of elements and therefore the whole structural performance in earthquake prone areas. In

* Corresponding author: kkoulouris@upnet.gr 
that sense, corrosive factor appears to be also responsible for the drop of ductility and puts at risk the durability of RC structures, namely its capacity to meet the requirements of serviceability, strength and stability throughout its design working life, without loss of utility or excessive unforeseen maintenance (Figure 1).

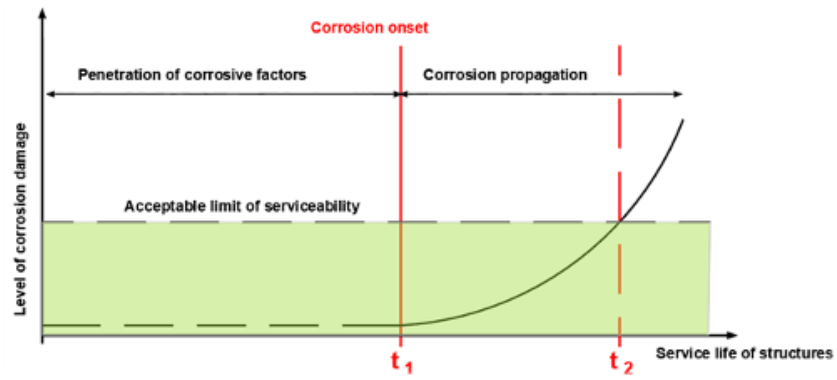

Fig. 1. Service life of structures towards level of corrosion damage.

The experimental data from several studies outline the adverse consequences of corrosive factors. The non-uniform distribution of corrosion damage on the steel cross section is one of the primary cause of mechanical properties' degradation, which has been studied by many researchers [1-5]. Moreover, the generated iron oxides on steel's surface due to corrosion lead to cracking and spalling of concrete cover and corrosion impairs the interface between steel and concrete and therefore affects the bond between them.

In continuance, structures, such as highway bridges, are subjected to increased number of cycles into the inelastic range and the repeated stress results in fatigue damage, notwithstanding the corrosive factor. Sheng and Gong have previously demonstrated that seismic events can be simulated by low cycle fatigue tests on steel reinforcement [6]. A plethora of studies has demonstrated the premature aging of RC structures due to low cycle fatigue [7-9]. Moreover, experimental observations demonstrated that severe corrosion impairs the fatigue accumulation and drop the useful life of a structure, especially at low strain amplitudes. In that sense, several studies have been conducted to investigate the coupled effect of dynamic loading along with the corrosive environment in RC structures [1,10-19].

Even though there are several studies indicating the severe effects in the structural integrity of RC structures due to corrosion and seismic loads, the international regulations do not determine recommendations on degradation rules of $\mathrm{RC}$ elements, taking into account the deterioration of materials. An important step towards this direction is standards of EN 206 where coastal regions' structures should adopt minimum requirements for concrete class in relation to exposure class.

From a financial perspective, corrosion is a considerable challenge and one of the most significant costs faced across the world, with enormous costs for repairing damaged structures (Figure 2). 


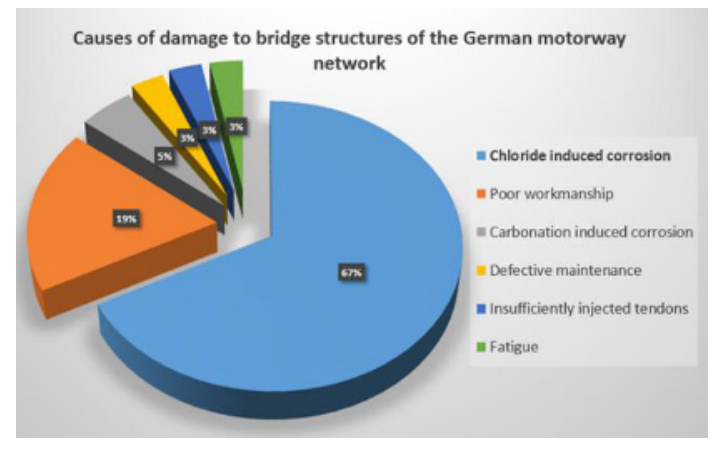

Fig. 2. Causes of damage to bridge structures of the German motorway network.

\section{Experimental procedure}

In the present study, which is part of an ongoing research, an experimental investigation had been conducted, so as to account for the effect of different exposed to corrosion length on reinforcing steel bars, which subsequently affects the structural performance and service time of RC structures.

In order to examine the corrosion resistance of the material, accelerated corrosion tests were carried out via the impressed current density corrosion method. Upon completion of the corrosion tests, fatigue tests were performed to assess the seismic performance of all groups of steel reinforcement.

\subsection{Specimen geometry and materials}

The experiments of this study were conducted on ribbed steel reinforcing bars of $16 \mathrm{~mm}$ nominal diameter and of B500c class. The chemical composition of steel B500c is given in Table 1. Totally, hundred and eighty specimens were cut, each with a total length of 300 $\mathrm{mm}$ and different exposed to corrosion lengths. Prompted by previous studies of the authors, in order to probe the corrosion consequences in different exposed lengths, the rebars were subdivided into two groups, namely "short" and "long" specimens, with different length free to be corroded and the rest of rebar's length was protected with a wax layer, as it is shown in Figure 3. Furthermore, each group was subdivided in two different exposed lengths, namely 1 and $2 \mathrm{~cm}$ for the "short" specimens and 10 and $12 \mathrm{~cm}$ for the "long" specimens, respectively.

Table 1. Chemical composition of reinforcing steel (\% by wt.).

\begin{tabular}{|c|c|c|c|c|}
\hline Element & $\mathbf{C}$ & $\mathbf{M n}$ & $\mathbf{S i}$ & $\mathbf{C r}$ \\
\hline \% by wt. & 0.21 & 1.04 & 0.2 & 0.17 \\
\hline
\end{tabular}



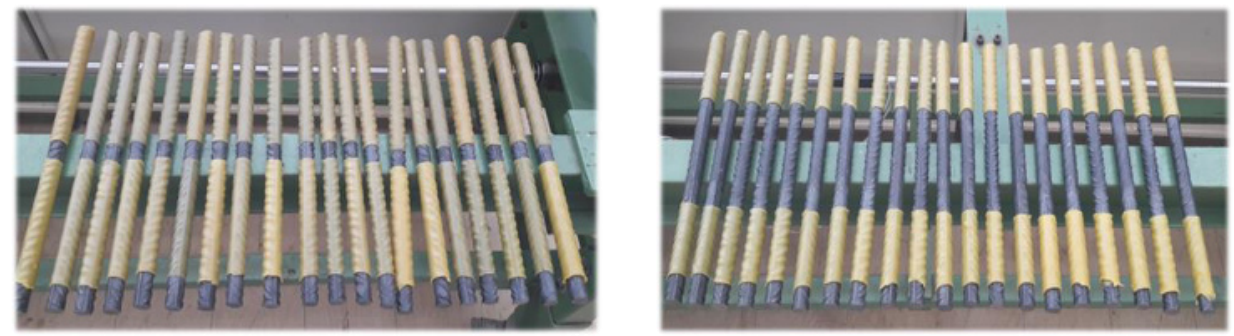

Fig. 3. Preparation of the "long" specimens (exposed length $12 \mathrm{~cm}-$ left) and "short" specimens (exposed length $2 \mathrm{~cm}$ - right)

\subsection{Accelerated corrosion technique}

Since corrosion phenomenon is a slow natural process, laboratory methods have been developed to simulate and accelerate the natural process. Each group of rebars was subjected to accelerated corrosion method via impressed current density technique.

Splash and tidal environments are the most aggressive cases, given the high chloride concentration and the wetting- drying cycles [20-21]. Hence, a cyclic exposure was performed, with 8 hours wet, by impressing current density of $1 \mathrm{~mA} / \mathrm{cm}^{2}$ on the specimens, and 16 hours in dry mode. In order to obtain different corrosion levels, specimens were subjected to ten different exposure times, these being $25,50,75,150,300,400,500,600$, 800 and $1000 \mathrm{~h}$, respectively. All specimens remained in the cells, filled with $5 \%$ sodium chloride $(\mathrm{NaCl})$ solution by the weight of water, as shown in Figure 3. After the exposure the specimens were cleaned and the oxide layer was removed from the specimens' surfaces using a bristle brush, according to the ASTM G1-03 [22], so as to estimate the level of corrosion damage.

\subsection{Mechanical Tests}

Upon the completion of accelerated corrosion process, fatigue tests were carried out on non-corroded and corroded specimens, of all cases, with a preliminary protocol for lowcycle fatigue tests after Spain's and Portugal's standards [23-24]. Three levels of imposed deformation were adopted for the execution of hysteretic cycles: $\pm 1.0 \%, \pm 2.5 \%$ and $\pm 4.0 \%$. Furthermore, the free length of the sample was assumed equal to be 6 times the bar's diameter (6Ø), namely $96 \mathrm{~mm}$, in order to perfectly represent the conditions of longitudinal rebars in RC elements of buildings designed in high ductility classes, according to Eurocode 8 [25].

\section{Results - Discussion}

The results of the experimental work are summarised in the aforementioned Fig. 4, 5 and 6. In particular, the outcomes are demonstrated along with results from previous experimental studies. 


\subsection{Influence of exposed length on mass loss of steel bars}

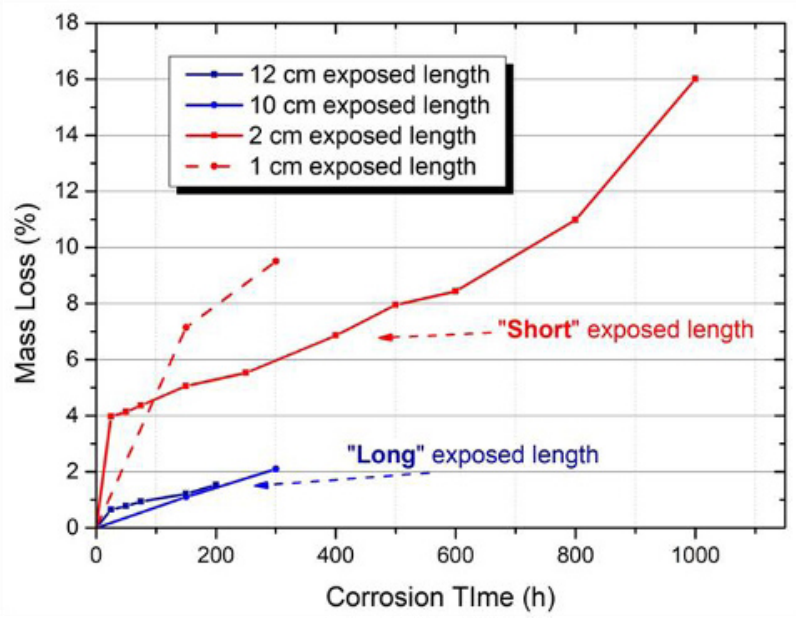

Fig. 4. (A) Percentage mass loss in respect to the corrosion exposure time

Figure 4 depicts the percentage mass loss of "short" and "long" specimens; for the case of "long" specimens up to $300 \mathrm{~h}$ corroded conditions and for "short" up to $1000 \mathrm{~h}$ corroded conditions. Ii is perceived visually that even if all groups of steel specimens had imposed by equal values of current density, the different exposed-to-corrosion length resulted in different corrosion rate of steel reinforcement. More specific, specimens with "long" exposed length recorded low corrosion levels of about $2 \%$ in $300 \mathrm{~h}$ corroded conditions, whereas "short" specimens (with limited exposed length) indicated greater values of mass loss; 4 times higher values for $1 \mathrm{~cm}$ - length exposed and 3 times higher values for $2 \mathrm{~cm}$ lengh exposed specimens, for $300 \mathrm{~h}$ corroded conditions.

It becomes apparent that the exposed-to-corrosion length and covered length (geometry) of reinforcing bars plays a key role in the resulting corrosion damage. The observations extracted from Figure 4 highlight the effect of differential aeration corrosion on the corrosion rate of steel bars. More specific, the differential aeration corrosion refers to each specimen, when different parts of which are exposed to different concentrations of oxygen. In that sense, as already demonstrated in previous work of the authors [26, 27], specimens with a shorter exposed length showed greater mass loss in comparison with specimens of the same total length but with longer exposed length, as the corrosion phenomena were bounded to a smaller area. In that manner, the parameter of exposed length affects not only the corrosion rate (percentage mass loss) but also the surface damage of corroded steel bars. In particular, steel bars with short exposed to corrosion length depict pitting corrosion with reduction of cross section locally, whereas steel bars with long to corrosion length denote uniform type of corrosion damage (Figure 5). In continuance, the different type of corrosion damage has significant effect on mechanical behaviour of steel reinforcing bars. 


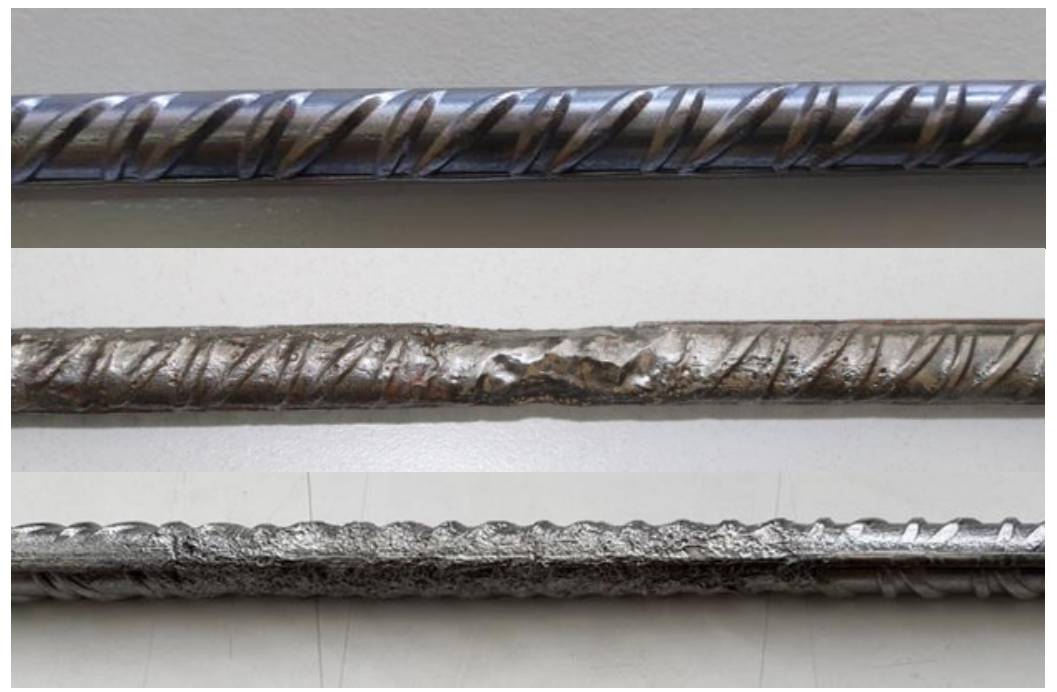

Fig. 5. Non corroded steel bar (up), corrosion damage on short exposed length (middle) and corrosion damage on long exposed length (bottom)

Extrapolating the above presented corrosion results of steel bars to the consequences of corrosion on real structures, questions are raised about the adopted methods of protecting $\mathrm{RC}$ elements against environmental actions. In the last two decades, the design standards worldwide, such as BS EN 206, have set values of minimum cover thickness and minimum concrete class in order to passivate the steel reinforcement from the corrosive factors. However, the existence of cracking in concrete cannot be avoided, resulting in conditions such as those considered in the present study, i.e. shorter or longer lengths without corrosion. Hence, the parameter of exposed to corrosion length or steel bars should be examined and taken into account for the assessment of corrosion damage or RC elements.

\subsection{Influence of corrosion damage on fatigue behavior}

Due to the fact that specimens with short exposed to corrosion length demonstrated severe corrosion damage, with high values of percentage mass loss, the fatigue behavior of this group was studied. The fatigue life prediction is significant in seismic analysis of Reinforced Concrete elements. Thus, fatigue tests in constant strain amplitudes $\pm 1.0 \%$, $\pm 2.5 \%$ and $\pm 4.0 \%$, were conducted in order to simulate constant seismic blocks and subsequently predict the fatigue life of reinforcing bars performing regression analysis, via the Coffin-Manson model (Figure 6). 

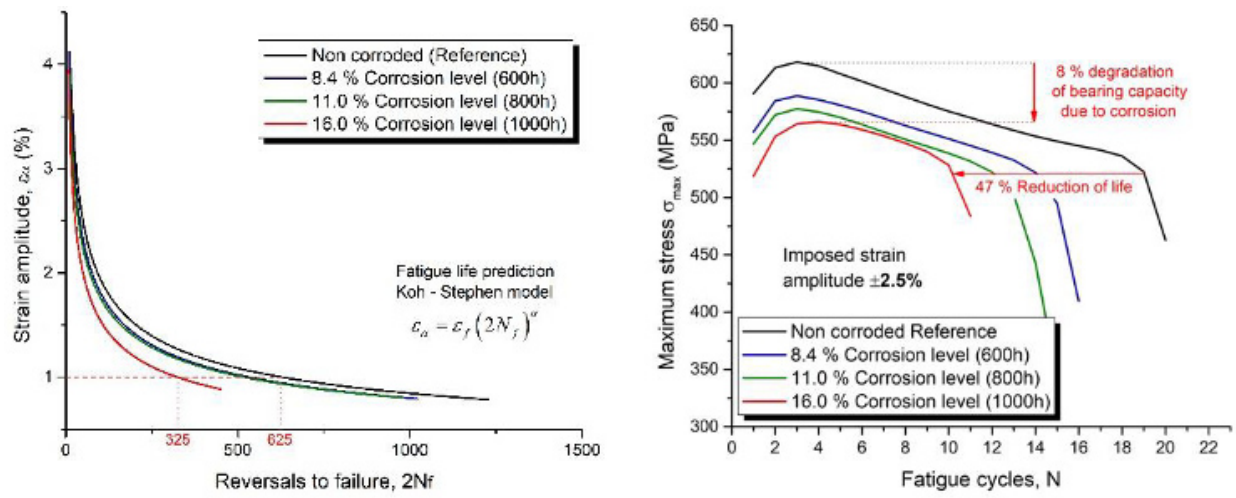

Fig. 6. (a) Fatigue life prediction and (b) reduction of bearing capacity of corroded reinforcing bars.

It is obvious from figure 6a that the increase of corrosion level reduces the service life of steel reinforcement. The significant influence of corrosion factor on mechanical degradation of steel bars is indicated mainly in low ranges of strain amplitude, namely below $\pm 2.5 \%$, where the predictive curves differ due to corrosion factor. More precisely, for strain amplitude equal to $\pm 1.0 \%$, reversals to failure reduced from 625 to 325 , for a corresponding mass loss equal to $16 \%$. In contrast, in greater ranges of strain amplitudes i.e. $\pm 4.0 \%$, the resulting corrosion damage is owed to inelastic buckling phenomena, which predominate towards the corrosive factor and are crucial for the failure. All the above are in good agreement with previous experimental studies in international literature [9, 28].

Besides the significant reduction of material's ductility and service life, the bearing capacity is also degraded over the repeated cycles. As shown in figure 6b, damage is accumulated due to both corrosion and fatigue loads, which subsequently drop the bearing capacity of steel bars, indicating the influence of loading history effect on their mechanical behavior. Up to date, during seismic analysis of RC elements, the peak value of ground acceleration is taken into account, neglecting both the loading history effect and the corrosion factor. Hence, since there is need to develop and enhance the current regulations these findings can contribute towards this direction.

\section{Conclusions}

The following conclusions are drawn from the present study:

- The parameter of exposed length of steel reinforcement is a significant influencing factor in its corrosion damage, since specimens of steel bars with limited (to corrosion) exposed length indicate greater values of mass loss.

- The increase of corrosion level and the resulting pit geometry on steel reinforcement reduces their seismic response affecting mainly the ductility of material in terms of dissipated energy capacity and its useful life time.

- The significant influence of corrosion factor on mechanical degradation of steel bars is indicated mainly in low imposed strain ranges, below $\pm 2.5 \%$, whereas in greater ranges the occurence of buckling phenomena determine the failure mechanism of corroded steel bars.

\section{References}


1. Fernandez I, Bairán JM, Marí AR. Mechanical model to evaluate steel reinforcement corrosion effects on $\sigma-\varepsilon$ and fatigue curves. Experimental calibration and validation. Engineering Structures. 2016; 118:320-333

2. Tahershamsi M, Fernandez I, Lundgren K, Zandi K. Investigating correlations between crack width, corrosion level and anchorage capacity. Structure and Infrastructure Engineering. 2017; 13(10):1294-1307. DOI: 10.1080/15732479.2016.1263673

3. Zhang W, Song X, Gu X, Li S. Tensile and fatigue behavior of corroded rebars. Construction and Building Materials. 2012; 34:409-417

4. Sun X, Kong H, Wang H, Zhang Z. Evaluation of corrosion characteristics and corrosion effects on the mechanical properties of reinforcing steel bars based on threedimensional scanning. Corrosion Science. 2018; 142:284-294

5. Andisheh K, Scott A, Palermo A, Clucas D. Influence of chloride corrosion on the effective mechanical properties of steel reinforcement. Structure and Infrastructure Engineering. 2019; 15(8):1036-1048

6. Sheng, G.M.; Gong, S.H. Investigation of low cycle fatigue behavior of building structural steels under earthquake loading. Acta Metall. Sin. Engl. Lett. 1997, 10, 5155.

7. Hawileh, R.A.; Abdalla, J.A.; Oudah, F.; Abdelrahman, K. Low-cycle fatigue life behaviour of BS 460B and BS B500B steel reinforcing bars. Fatigue Fract. Eng. Mater. Struct. 2010, 33, 397-407.

8. Apostolopoulos, C.A.; Rodopoulos, C.A. Inelastic cyclic behavior of as-received and pre-corroded S500s Tempcore steel reinforcement. Int. J. Struct. Integr. 2010, 1, 5262.

9. Kashani, M.; Barmi, A.K.; Malinova, V.S. Influence of inelastic buckling on low-cycle fatigue degradation of reinforcing bars. Constr. Build. Mater. 2015, 94, 644-655.

10. Kashani, M.M.; Lowes, L.N.; Crewe, A.J.; Alexander, N.A. Finite element investigation of the influence of corrosion pattern on inelastic buckling and cyclic response of corroded reinforcing bars. Eng. Struct. 2014, 75, 113-125.

11. Meda, A.; Mostosi, S.; Rinaldi, Z.; Riva, P. Experimental evaluation of the corrosion influence on the cyclic behaviour of RC columns. Eng. Struct. 2014, 76, 112-123.

12. Dolley, E.J.; Lee, B.; Wei, R.P. The effect of pitting corrosion on fatigue life. Fatigue Fract. Eng. Mater. Struct. 2000, 23, 555-560.

13. Veerman, R.; van Breugel, K.; Koenders, E. Effect of Corrosion on the Fatigue Service-Life on Steel and Reinforced Concrete Beam. In Proceedings of the fib Symposium, Copenhagen, Denmark, 18-20 May 2015.

14. Yi, W.; Kunnath, S.K.; Sun, X.; Shi, C.; Tang, F. Fatigue Behavior of Reinforced Concrete Beams with Corroded Steel Reinforcement. ACI Struct. J. 2011, 107, 526533.

15. Apostolopoulos, C.A.; Konstantopoulos, G.; Koulouris, K. Seismic resistance prediction of corroded S400 (BSt420) reinforcing bars. Int. J. Struct. Integr. 2018, 9, 119-138.

16. Afsar E., Kashani M.M., 'Exploring the impact of chloride-induced corrosion on seismic damage limit states and residual capacity of RC structures', Structure and Infrastructure Engineering 14 (6) (2017) 714-729

17. Li, X., Liang, Y.-S., Zhao, Z.-H., \& Ly, H.-L., 'Low-cycle fatigue behavior of corroded and CFRP-wrapped reinforced concrete columns', Construction and Building Materials, 101 (2015) 902-917 
18. Vasco, Marina Cardoso, Panagiota V. Polydoropoulou, Apostolos Chamos and Sp.G. Pantelakis. "Effect of corrosion and sandblasting on the high cycle fatigue behavior of reinforcing B500C steel bars." Fracture and Structural Integrity 11 (2017): 9-22.

19. Apostolopoulos C., Papadopoulos M., 'Tensile and low cycle fatigue behaviour of corroded reinforcing steel bars S400', Constr Build Mater. 21 (4) (2007) 855-64.

20. BSI (British Standards Institution). Concrete. Part 1: Specification, Performance, Production and Conformity; EN 206-1; BSI: London, UK, 2000

21. Apostolopoulos, C.A.; Drakakaki, A.; Basdeki, M. Seismic assessment of a reinforced concrete column under seismic loads. Int. J. Struct. Integr. 2019, 10, 41-54.

22. ASTM International. ASTM G1-03, Standard Practice for Preparing, Cleaning, and Evaluating Corrosion Test Specimens; ASTM International: West Conshohocken, PA, USA, 2017

23. Especificação LNEC Varões de aço. A400 NR de Ductilidade Especial Para Armaduras de Betão Armado Características, Ensaios e Marcação; AO, LNEC E 4552010. 2010.

24. UNE. Norma Espanola Experimental Barras Corrugadas de Acero Soldable con Caracteristicas Especiales de Ductilidad para Armaduras de Horigon Armado; UNE 36065 EX 2000; UNE: Madrid, Spain, 2000

25. CEN-European Comittee for Standardization. EN 1998-1:2005, Eurocode 8: Design of Structures for Earthquake Resistance-Part 1: General Rules, Seismic Actions and Rules for Buildings; CEN-European Comittee for Standardization: Brussels, Belgium, 2005.

26. Apostolopoulos, C.A.; Koulouris, K.; Basdeki, M. Damage Parameters of Rebars in Marine Environment and Fatigue Life. In Proceedings of the International Conference on Sustainable Materials, Systems and Structures (SMSS 2019), Rovinj, Croatia, 2022 March 2019.

27. Drakakaki, A.; Apostolopoulos, C.A. The size effect of rebars on the structural integrity of reinforced concrete structures, which are exposed to corrosive environments. MATEC Web Conf. 2018, 188, 03009.

28. Kunnath, S.K., Kanvinde, A., Xiao, Y. and Zhang, G. (2009), "Effects of buckling and low cycle fatigue on seismic performance of reinforcing bars and mechanical couplers for critical structural members", Technical Report CA/UCD SESM-09-01, California Department of Transportation, Sacramento, CA. 